\title{
PROSODIA RÍTMICA DE VOCALES CONTIGUAS EN INTERIOR DE PALABRA
}

\section{RHYTHMIC PROSODY OF THE CONTIGUOUS VOWELS WITHIN WORDS}

\author{
José Domínguez CAPARrós \\ UNED (Madrid)
}

\begin{abstract}
Resumen: El estudio de la prosodia rítmica de las vocales contiguas en interior de palabra se centra en el caso más ambiguo: $i$, $u$ átonas seguidas de $a, e, o, i, u$ tónicas. Se comenta el variado cuadro terminológico y conceptual de los principales prosodistas referido al asunto (Bello, Benot, Robles Dégano, Tomás Navarro Tomás) y se analizan los ejemplos de las palabras cruel, fiel, suave, ruido, ruina en algunas obras de Fray Luis de León, Fernando de Herrera, Luis de Góngora, José de Espronceda, Rubén Darío, Juan Ramón Jiménez, y en las poesías de Garcilaso de la Vega.
\end{abstract}

Palabras clave: prosodia (doble, inestable, rítmica), diéresis, sinéresis, hiato, diptongo.

Abstract: The study of the rhythmic prosody of the contiguous vowels within words focuses on the more ambiguous case: $i, u$ unstressed followed by $a, e, o, i, u$ tonic. We discuss the varied terminology and conceptual frame referred to the question of the main prosodists (Bello, Benot, Robles Dégano, Tomás Navarro Tomás) analyzing the examples of the words cruel, fiel, suave, ruido, ruina in some works of Fray Luis de León, Fernando de Herrera, Luis de Góngora, José de Espronceda, Rubén Darío, Juan Ramón Jiménez, and in the poetry of Garcilaso de la Vega.

Key words: prosody (double, unstable, rhythmic), diaeresis, 
syneresis, hiatus, diphtong. 
ue la prosodia rítmica de las vocales contiguas en interior de palabra es variable en algunos de los casos se comprueba por las divergencias entre los prosodistas cuando, en la descripción de los mismos, emplean los conceptos de hiato (azeuxis, adiptongo), diéresis, para la separación de vocales en interior de palabra; y sinéresis, diptongo o triptongo, para la unión. No faltan tampoco los comentarios sobre la inestabilidad prosódica en algunos ejemplos. Partiendo de unas notas sobre la diéresis, nosotros mismos hemos aludido a esta cuestión en un trabajo publicado en $2004^{1}$. Aunque tengamos muy claramente precisadas y aceptadas las definiciones de diptongo y triptongo, diéresis, azeuxis ${ }^{2}$ y sinéresis, desde el momento en que la distinción supone diferenciar entre una forma «normal» (diptongo, triptongo, azeuxis) y otra «figurada», «licenciosa» (diéresis, sinéresis), y dado que lo «normal» cambia según nos centremos en lo fijado como normativo o en lo variable del uso, no pueden extrañar las calificaciones distintas, e incluso contradictorias, para una misma división silábica. Notables ejemplos de esta multiplicidad de análisis pueden verse en nuestro mencionado trabajo sobre la diéresis.

Pero es que en la misma teoría se plantea la cuestión. Mariano José Sicilia, autor de la primera Ortología y Prosodia (1827, 1828), habla de «elasticidad prosódica» en el caso de una sílaba

${ }^{1}$ Domínguez Caparrós, José: «Para el estudio de la diéresis métrica». Rhythmica, 2004, II, 2, pp. 35-66; y también en Domínguez Caparrós, José: Nuevos estudios de métrica. Madrid: UNED, 2007, pp. 101-124.

${ }^{2}$ El concepto de azeuxis para la separación interior de vocales que no supone la ruptura de un diptongo, es decir, que no es diéresis, es propuesto en prosodia por RoBles DÉGANo, Felipe: Ortología clásica de la lengua castellana. Madrid: Marceliano Tabarés, 1905. Esta separación se ha llamado hiato en gramática y en fonética, pero en métrica hiato tiene el sentido específico de no realización de una sinalefa. Eduardo BENOT habla de adiptongación y adiptongo para estos casos en su Prosodia castellana i versificación. Madrid: Juan Muñoz SÁnchez, [1892], 3 tomos. 
formada por dos vocales con acento en la primera (trae, caen, brea, crían, veas, frío, río) ${ }^{3}$, o de «cierta especie de sinéresis o de diptongo imperfecto» en otros ejemplos ${ }^{4}$. El problema, que motiva precisamente el que se construyan tratados encaminados a encontrar unas reglas, es enunciado por Eduardo Benot cuando dice que estas reglas de la «emisión de muchas vocales en un solo tiempo silábico, o su aislamiento o independencia fonética, son, en primer lugar, complicadas, porque dependen de la NATURALEZA de las vocales, i de la circunstancia de estar con ACENTO o sin él...; i, en segundo lugar, no pueden abarcar todos los casos, por ser, en muchas ocasiones, potestativo, dependiente de la voluntad del que habla el desatar las vocales de un diptongo -(lo que se llama diéresis):

grandioso, grandịoso;

coetáneo, cọetáneo;

o bien el pronunciar en un tiempo silábico las de un adiptongo (lo que se llama sinéresis):

${ }^{3}$ Anota M. J. SiciLiA: «Algunos podrán pensar que no es diptongo, sino sinéresis lo que se comete en estos y en todos los demás casos en que las dicciones de este género se encuentran usadas con diptongo o sin él. Pero con igual razón podrían decir otros que en el caso de pronunciarse estas dicciones sin diptongo, se cometía la diéresis. A mi parecer estos dos modos de ver son igualmente engañosos. La sinéresis y la diéresis tienen de suyo el causar alguna violencia a la prosodia natural y espontánea de las dicciones en que se cometen, lo cual no se verifica en estas de que estamos tratando, ya sea que se usen con diptongo, o ya sea que corran sin él, con tal que se sepa ponerlo o quitarlo según lo requieran las circunstancias. Más fundado sería el decir que estas voces tienen cierta especie de elasticidad prosódica, por la cual se prestan o se rehúsan al diptongo según los casos en que se emplean». Lecciones elementales de ortología y prosodia. París: Librería Americana, t. IV, 1828, pp. 28-30, nota (a).

${ }^{4}$ En el caso de verbos terminados en ua, uе, uo, más pronombre: di-rrúa-se, excep-túe-se, ibid., p. 45. De «diptongo impropio» habla también Andrés Bello a propósito de la sinéresis en sílabas de dos vocales llenas (león, monosílabo, por ejemplo). Bello, Andrés: Principios de la ortolojía [sic] y métrica de la lengua castellana. Santiago de Chile: Imprenta de la Opinión, 1835, p. 46. Conocida es la dificultad de dar reglas que fijen la norma para la formación de diptongos o hiatos. Antonio Quilis concreta la dificultad en: el mismo fenómeno, el propio hablante (según el desarrollo de la tendencia antihiática de su habla) y la evolución de la lengua (antes se decía re-i-na, ve-in-te). Quilis, Antonio: Tratado de fonología y fonética españolas. Madrid: Gredos, 2002, 2. ${ }^{\text {e }}$ ed., reimpresión, p. 184. 
cạe, cáe;

cạos, cáos;

alzạos, alzáos...» $»^{5}$.

No han perdido significado las palabras de Marcelino Menéndez Pelayo en la carta prólogo a la obra de Felipe Robles Dégano, cuando dice que «gracias a esta obra, capital en la materia, dejará de ser un laberinto la teoría de la recta pronunciación de nuestra lengua, y de las leyes de nuestro ritmo, como todavía lo era, a pesar de los beneméritos y muchas veces afortunados esfuerzos de Sicilia, Bello y los tratadistas que les han sucedido» ${ }^{6}$. Efectivamente, las obras de Mariano José Sicilia (1827-1828), Andrés Bello (1835), Benot (1892) y Felipe Robles Dégano (1905) constituyen el corpus de primeros tratados sistemáticos fundamentales del estudio de la pronunciación española. En todos ellos, y en el que hoy sigue siendo el manual de referencia, el de Tomás Navarro Tomás, ocupa un lugar muy importante la prosodia rítmica, pues el silabeo del verso encuentra en el metro un apoyo objetivo. Robles Dégano, por lo demás, dedica el libro cuarto de su obra a la ortología silábica, y empieza: «Entramos en la materia más importante de esta obra, por ser la más nueva, la más ignorada hasta el presente, y la que con más afán he trabajado» ${ }^{7}$. Al empezar el estudio de los sonidos agrupados, Tomás Navarro Tomás establece la tendencia a formar un grupo monosilábico en el caso de conjunto de vocales, pero señala que hay razones históricas, analógicas o eruditas que se oponen y dan lugar a vacilaciones que llegan hasta la doble forma de pronunciación de una palabra. Es imposible dar reglas fijas para las vacilaciones; solo es posible «tratar de señalar en cada caso la forma que hoy tiene un uso más corriente en la pronunciación correcta». Y sigue: «Ofrece un valor principal a este propósito el testimonio de los buenos poetas modernos. El oído de un buen

\footnotetext{
${ }^{5}$ Benot, E.: Prosodia castellana, cit., I, p. 277. El lugar central que ocupa en la obra de Benot el problema de la pronunciación de las vocales en contacto se refleja en la utilización del subpunto (un punto debajo de la vocal que no se une en la pronunciación a la que sigue) en todo el texto de su voluminosa obra.

${ }^{6}$ Robles DÉgano, Felipe: Ortología clásica, cit., pp. V-VI.

${ }^{7}$ Ibid., p. 212. Sabido es que Robles Dégano se basa en el análisis de un inmenso corpus de poesía de los siglos XVI y xvII de la colección Rivadeneyra (BAE).
} 
poeta es siempre un excelente guía en lo que se refiere, dentro de su idioma, al acento y al cómputo silábico de las palabras» ${ }^{8}$.

Antes de la moderna constitución de la ortología como disciplina que estudia la pronunciación, encontramos en Juan Caramuel el tratamiento más sistemático de la sílaba, en el capítulo I del libro I de su Rítmica, «Sobre las letras, las vocales y las sílabas», especialmente los artículos III («Sobre las sílabas», con una nota «Sobre las figuras gramaticales»), el IV («Sobre el disílabo, el diptongo, la sinéresis y la diéresis») y el VII («Sobre la sinalefa»). La nota sobre las figuras gramaticales es destacable porque es donde quedan establecidas claramente las particularidades de la sílaba métrica, pues, de las seis figuras que elige, todas tienen que ver con ella, menos la síncopa. Esta sería más bien figura poética (spirtu por espíritu, o carbunclo por carbúnculo), pues no hay evidencia de un poder del metro sobre la forma de la palabra. Las otras cinco sí tienen que ver con la sílaba métrica: disílabo [azeuxis], diptongo, diéresis, sinéresis, sinalefa ${ }^{9}$. Falta la referencia al hiato métrico como fenómeno opuesto a la sinalefa para disponer de un cuadro conceptual muy

${ }^{8}$ NaVArro Tomás, Tomás: Manual de pronunciación española. Madrid: CSIC, [1918] $1968,14 .^{a}$ edición, pp. 148-149. Es cierto que en nota aclara como diferencia «la libertad que el poeta puede tomarse de silabear o acentuar algunas palabras de cierto modo que, por arcaísmo o por cultismo, puede, en la conversación, no ser de uso común, como ocurre, por ejemplo, en vi-a-je-ro por via-je-ro, i-di-o-ma por i-dio-ma, cam-bi-ar por cam-biar, parasito por parásito» (p. 149). QuiLis, A.: Tratado de fonología, cit., p. 184, reconoce el valor del verso: «Los poetas, con el dominio más o menos intuitivo de la lengua, suelen tratar correctamente el fenómeno [del hiato y el diptongo]».

${ }^{9}$ Caramuel, Juan: Primus Calamus. Tomus II. Ob oculos exhibens Rhythmicam. Apud Sanctum Angelum della Fratta: ex typographia Episcopali Satrianensi, 1665; Primer Cálamo. Tomo II. Rítmica, edición y estudio preliminar de Isabel Paraíso. Valladolid: Universidad de Valladolid, Universidad de Murcia, UNED, Junta de Castilla y León, 2007. Hay que destacar en la obra de Caramuel la descripción del uso poético referido a las uniones de dos vocales en interior de palabra partiendo de las veinticinco posibilidades teóricas de combinación de las cinco vocales entre sí. Es la forma en que la ortología moderna plantea el estudio de estas combinaciones. Y en cuanto a los ejemplos, es muy destacable la atención prestada por Caramuel a Góngora. Por todo ello, puede considerarse al erudito madrileño como el fundador de la prosodia rítmica española. 
próximo al que en la teoría métrica española sirve de marco para la comprensión de la sílaba métrica formada por concurrencia de vocales.

Este cuadro sería el siguiente:

\begin{tabular}{|c|c|c|}
\hline $\begin{array}{c}\text { VOCALES } \\
\text { CONTIGUAS }\end{array}$ & Unión & Separación \\
\hline $\begin{array}{l}\text { Interior de } \\
\text { palabra }\end{array}$ & $\begin{array}{c}\text { diptongo, triptongo } \\
\text { sinéresis }\end{array}$ & $\begin{array}{c}\text { diéresis } \\
\text { (azeuxis, hiato, adiptongo) }\end{array}$ \\
\hline $\begin{array}{c}\text { Entre } \\
\text { palabras }\end{array}$ & Sinalefa & hiato (dialefa) $^{10}$ \\
\hline
\end{tabular}

A la vista de este cuadro, podemos decir que la cuestión en la que me voy a centrar es en la de las vocales contiguas en interior de palabra y que los conceptos con los que tenemos que tratar son los de diptongo, triptongo / diéresis; (azeuxis,hiato, adiptongo) / sinéresis.

Adelanto un ejemplo de algo con lo que no será raro encontrarnos más adelante en el análisis de casos concretos. Tiene que ver con la inestabilidad de estos conceptos en algunas ocasiones para la clasificación de los ejemplos. Bello, hablando del caso de la concurrencia de dos vocales llenas en posición postónica de palabra (Dánao, Cesáreo), dice que la combinación forma dos sílabas, pero añade: «Como los poetas hacen casi siempre diptongos, pudiera pensarse en invertir la regla y decir que son diptongos que admiten diéresis por licencia. Pero en nuestra

${ }^{10}$ Entre paréntesis van los términos no generalizados como tecnicismos métricos. El hueco más notable es el de la separación natural de vocales contiguas en el interior. Benot utilizaba el término de adiptongo. A veces se usa el de hiato, en sentido gramatical, que tiene el inconveniente de que ya tiene en métrica desde Herrera, por ejemplo, el sentido de no sinalefa. Para solucionar este problema, desde la traducción del manual de Rudolf Baehr, en 1970, se emplea con más frecuencia en métrica española, para la separación de vocales entre palabras, el término de dialefa. Caramuel llamó disílabo a la separación de vocales en sílabas distintas. Robles Dégano fue quien propuso el término de azeuxis para «la contigüidad de dos vocales que naturalmente no se unen para formar una sílaba; v. g., Te-ófilo, tra-ído, re-úne, cri-ar». RoBLEs DÉGANo, Felipe: Ortología clásica, cit., p. 34. El DRAE (2001, 22. a edición) define azeuxis así: «Hiato, encuentro de dos vocales que se pronuncian en sílabas diferentes». Aunque la Academia no distingue si es en interior de palabra o entre vocales de palabras contiguas, parece deducirse que se refiere al interior (como en el caso del hiato gramatical), pues en la entrada de hiato hay una acepción propia para el hiato en métrica. 
prosodia es más familiar y frecuente la sinéresis que la diéresis» ${ }^{11}$. Dudas de este tipo explican las divergencias y discusiones con que nos vamos a encontrar al comparar lo que dicen unos prosodistas con lo que dicen otros.

II

Dentro de la combinación de vocales en interior de palabra, el grupo más difícil de regular es el formado por vocal átona débil $(i, u)$ más vocal tónica (llena $-a, o, e-$, o débil $-i, u-$ ). Andrés Bello considera que la combinación de débil átona y llena tónica unas veces forma diptongo y otras no: Dios es constantemente monosílabo; fiemos es naturalmente trisílabo. Trata de dar la explicación de todos los casos formando seis grupos. En las explicaciones desempeñan un papel central: la etimología (ié, ué procedentes de $e$, o tónicas latinas «forman diptongos absolutamente indisolubles»); la analogía de la conjugación (fío, fi-a-mos; cam-bio, cam-bia-mos; la sinéresis es más fácil que la diéresis en estos casos); la terminación verbal (ié es diptongo indisoluble en terminaciones verbales: pretérito de indicativo -ieron, imperfecto de subjuntivo -iese..., futuro de subjuntivo -iere..., gerundio -iendo); la analogía de las derivaciones (brío, bri-o-so; na-ví-o, na-vi-e-ro; glo-ria, glo-rie-ta; am-bi-ción, am-bi-cio-so); sustantivos verbales en -ion forman diptongo indisoluble (leer > lección). Pero el último grupo está reservado precisamente a los ejemplos que no caben en los cinco anteriores. Se caracteriza por la variación del uso: «En los demás casos es necesario atender al buen uso, según el cual la combinación forma a veces un diptongo indisoluble, como en Dios, pie, fue, y otras veces diptongo soluble, o dos sílabas que se prestan sin la menor violencia a la sinéresis [subrayo], como en Diana, suave, que son arbitrariamente disílabos o trisílabos» ${ }^{12}$. Así pues, partiendo del razonamiento de Bello podremos añadir por nuestra parte que si consideramos que suave es bisílabo podría hablarse de diéresis en el caso de un silabeo como trisílabo; mientras

${ }^{11}$ Bello, Andrés: Principios de la ortolojía [sic] y métrica de la lengua castellana, cit., p. 49.

12 Ibid., p. 48. 
que si lo pensamos como trisílabo, habrá sinéresis si aparece en verso como bisílabo. En definitiva, sería explicable la variación siguiente: sua-ve, bisílabo, será diptongo o sinéresis; su-a-ve, trisílabo, será azeuxis o diéresis.

Añádase a lo anterior las peculiaridades del uso poético, también considerado por Andrés Bello, para darnos cuenta de la riqueza de matices que puede adquirir el comentario de la prosodia rítmica en estos casos. En el grupo de la analogía de la conjugación, dice el venezolano que «es frecuente en los poetas hacer monosílaba la combinación iá o uá en fiamos, variamos, valuamos, pero dudo que un buen versificador la haya hecho jamás disílaba cuando forma naturalmente diptongo, como en cambiamos, fraguamos, acopiamos, aguamos». En los casos de analogía de las derivaciones, se permite al poeta la sinéresis en el caso de que por su procedencia la combinación no forme diptongo (bri-o-so > brio-so; na-vi-e-ro > na-vie-ro), pero en los casos de diptongo «este es por lo común indisoluble, bien que por una licencia poética que no deja de halagar al oído, se halla a veces disuelto en los adjetivos derivados que terminan en ioso, y uoso, como gracioso, glorioso, fastuoso, majestuoso, etc., en que, según la pronunciación ordinaria, las combinaciones ió, uó son diptongos» ${ }^{13}$.

En el caso de que la vocal tónica, la segunda del grupo, sea débil también, resulta imposible una clasificación; solo cabe observar la «variedad en el uso». Hay diptongo indisoluble, según Bello, en: fui, cuita, cuido, descuido; diptongo disoluble «o si se quiere dos sílabas que admiten fácilmente la sinéresis, como en ruin, ruina, ruido, viuda»; influencia de la analogía verbal en casos como hu-yo > hu-i, hu-i-mos, $h u-i-a$, $h u-i-d a$, aunque en estos casos «se permite la sinéresis a los poetas»; dificultad extrema de sinéresis en el caso de que se duplique la vocal, piísimo, duúnviro ${ }^{14}$. Hay que destacar el caso de ruin, ruina, ruido, viudo que, de forma paralela al comentado de Diana, suave, puede considerarse tanto diptongo disoluble como dos sílabas que admiten la sinéresis sin dificultad.

$\overline{{ }^{13}}$ Ibid., pp. $47-48$.
${ }^{14}$ Ibid., p. 49. 
Vista la descripción que hace Bello del grupo de vocales interiores formado por vocal átona débil $(i, u)$ más vocal tónica (lle$n a-a, o, e-$, o débil $-i, u-)$, nuestro comentario se va a centrar en el estudio de esta combinación. Dos son las tareas que nos proponemos llevar a cabo: contraste de la doctrina de Bello con la de otros prosodistas posteriores, por un lado, y estudio particular de las palabras cruel, fiel, suave, ruido, ruina, por otro, para ilustrar la riqueza del uso poético y de la percepción del mismo.

Para Eduardo Benot, toda vocal absorbible $(i, u)$ inacentuada «por regla general» forma diptongo con cualquier vocal acentuada contigua, vaya antes o después (gaita, anciana, sauce, cuida, triunfo...), aunque el «uso desata a veces estas combinaciones vocales» (ruin, vịuda) ${ }^{15}$. Entre las conclusiones del amplio estudio que dedica a la diptongación (el libro III completo, pp. 5-293 del tomo II de su obra), hay dos que se refieren al tipo de combinación que nos interesa en este trabajo. La número 5 , que dice que «una absorbente acentuada [á, ó, é] puede ligarse o no a una absorbible [i, u]»: vịola, vióla; y la número 6, que dice que «una absorbible acentuada puede ligarse o no a otra absorbible»: ruịna, cuita $^{16}$. En conclusión, no hay una regla fija para la prosodia de la combinación de vocales en que una absorbible (débil o cerrada: $i, u$ ) es contigua a otra vocal tónica. Hablará de doble prosodia en el caso de absorbible inacentuada seguida de absorbente con acento: grandioso, grandioso; majestuoso, majestuoso. Ante los casos de doble prosodia, ¿cuándo hay que hablar de sinéresis - «un adiptongo natural se funde en un tiempo silábico» -o de diéresis- «un diptongo natural se desata en dos tiempos»-? ${ }^{17}$; o dicho de otra manera, ¿qué es lo natural en los casos de doble prosodia, el diptongo o el adiptongo? Eduardo Benot plantea nítidamente el problema: «Existen voces en que no se sabe si para la doble prosodia se comete diéresis o sinéresis [subrayo], por no ser fácil asegurar cuál es la prosodia más usual y corriente, ni cual la artificial [...]. I tanta es la dificultad, que a

\footnotetext{
${ }^{15}$ B $E$ ENOT, E.: Prosodia, cit., I, pp. 281-282. El asunto de los diptongos, triptongos y sinalefa es tan importante que al mismo se dedica el tomo II de la obra de E. Benot, con 584 páginas.

${ }^{16}$ Ibid., II, p. 293.

${ }^{17}$ Ibid., II, p. 562.
} 
veces no puede asegurarse cómo mediría un autor determinado verso». Por ejemplo, el siguiente octosílabo de Calderón:

Sen-táos-qu'el viento su-a-ve // Sen-ta-os qu'el viento sua-ve ${ }^{18}$.

Como muy bien apunta Benot, el problema está en determinar con exactitud qué es lo usual, lo natural, a partir de lo cual decidir la prosodia que es ejemplo de diéresis o la que lo es de sinéresis. Vamos a encontrar la manifestación de este problema cuando pasemos revista a los análisis de las palabras que estudiaremos más adelante.

Felipe Robles Dégano trata de los grupos de vocales contiguas que nos interesan en los capítulos IV y V del libro cuarto, dedicados a las combinaciones tónicas de dos débiles y a la de débil átona seguida de fuerte tónica. Después de los análisis del extenso corpus de poesía de los siglos XVI y XVII, el sacerdote abulense tiene menos dudas que Bello o Benot a la hora de establecer la norma a partir de la cual hablar de diéresis o sinéresis. Es regla de su ortología la que dice: «Toda combinación tónica de dos vocales débiles es azeuxis: v. gr., en drúida, pĩisimo, orĩundo, flũir». Además de algunas excepciones a esta regla, por «uso cambiado [subrayo] es permitida la sinéresis en Ruiz, juicio, ruido, ruin y ruina. Primitivamente los poetas guardaban en ellos la azeuxis, como debía ser» ${ }^{19}$. He subrayado la expresión uso cambiado porque se refiere al cambio histórico, uno de los factores que es tenido muy en consideración por Robles Déga$\mathrm{no}^{20}$. Las reglas de la combinación de débil átona y fuerte tónica (uá, ué, uó; iá, ié, ió) son bastante complejas. Así la referida a uá, uó dice que estas combinaciones «son siempre azeuxis, si no van detrás de consonante gutural». Así, en la palabra suave, una

\footnotetext{
$\overline{18}$ Ibid., II, p. 77.

${ }^{19}$ Nótese el uso de la tilde de ñ sobre la vocal primera del grupo cuando no se une de forma natural a la siguiente en una sílaba, es decir, cuando hay azeuxis de débil átona seguida de tónica (p. 35). Son excepciones los diptongos en: Ruy, muy; triunfo, viuda y monsiur; derivados de nombres en gua (agüita, de agua); buitre, cuido, cuita, Luis, Monjuí, muito (gallego y portugués), fui, pretérito de ser o ir. RoBles DÉgano, Felipe: Ortología clásica, cit., p. 249.

${ }^{20}$ Como ejemplo de historia de la prosodia, véase la explicación de las palabras juicio, ruido, ruin, ruina. Ibid., pp. 262-266.
} 
de las que estudiaremos, hay azeuxis: sũave. La regla referida a las combinaciones ié, ué, en las que entran dos de las palabras que estudiaremos (fiel, $\mathrm{cruel}$ ), dice que «las combinaciones ié, ué no derivadas de azeuxis, son generalmente diptongos». Aunque son excepciones, es decir, tienen azeuxis las palabras cliente, Lĩeo, Pírides, rĩel, rĩelo-as (del verbo rielar), Tĩestes, Viena; y con ué tienen azeuxis y son excepciones a la regla: Frũela, genũense, Josũé, ũeste [sic], Sũecia, Sũevia, Sũez. Ahora bien, las excepciones de la regla referida a ié, ué son de «tan difícil determinación, que a pesar de todo el trabajo y buena intención que he puesto en la materia, no presumo haberla agotado, de suerte que no se pueda exceptuar alguna palabra más o menos. La ignorancia, la vaguedad del uso en los poetas y la tendencia moderna a las contracciones [subrayo] son cosas que deben tenerse en cuenta para la determinación de una regla o excepción; pero cuando las razones en pro y en contra son casi iguales, el hacerlo autoritariamente pertenece a la Real Academia» ${ }^{21}$. En toda su verdad expresa F. Robles Dégano la dificultad de fijar lo natural, lo normativo a partir de lo que calificar de variante un uso distinto.

¿Qué nos dice sobre la cuestión Tomás Navarro Tomás? A la de autor del manual de pronunciación que sigue siendo referencia clásica, continuamente reeditado desde su aparición en 1918, el ilustre filólogo une la condición de ser el constructor del mejor monumento con que cuenta la métrica española, y lógicamente considera, como todos sus predecesores, el uso de los poetas. Dos vocales en interior de palabra forman diptongo en el caso de las «vocales $i, u$, combinadas entre sí o acompañada cada una de ellas por otra vocal», dando lugar a los diptongos: $a i, a u, e i$, $e u$, oi, ou (decrecientes: vocal más semivocal); ia, ie, io, iu, ua, ue, ui, uo (crecientes: semiconsonante más vocal). Tres vocales en interior de palabra se agrupan en los triptongos iai, iei, uai, uei. Las vocales en interior de palabra frecuentemente no

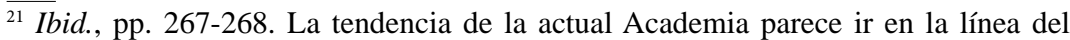
reconocimiento de la diversidad de usos en la lengua española más que en la de la imposición de una norma. T. Navarro Tomás también asigna un papel a la Academia Española, que podría decir «la forma de pronunciación que se considera más conveniente» en casos de vacilación. NAVArro Tomás, T.: Manual de pronunciación, cit., p. 9. 
forman diptongo, sino que «por tradición gramatical constituyen sílabas distintas». Se llama hiato precisamente el «efecto prosódico» que produce la pronunciación en estos casos $^{22}$. Ahora bien, estos hiatos de la tradición gramatical pueden reducirse a una sola sílaba en el uso, en la lengua hablada, dando lugar a la sinéresis. Si interpretamos bien, el cuadro conceptual de Tomás Navarro Tomás comprende: DIPTONGO, TRIPTONGO (sílaba con los grupos de vocales mencionados), HIATO (dos sílabas, en grupos de vocales distintos de los mencionados antes para los diptongos, como, por ejemplo: ii, uu, aa, ee, oo, ea, oa, eo, oe, ae, ao; $\mathrm{y}$ tradición gramatical en grupos que podrían formar diptongo pero que no lo hacen), sINÉRESIs (reducción de los hiatos a una sílaba) ${ }^{23}$. Respecto del cuadro conceptual de la tradición de la teoría prosódica, llama la atención que desaparece el concepto de lo que se entendía por diéresis, que, en todo caso, quedaría integrado como una forma de hiato. Por lo demás, cuando se trata de oponer las posibilidades de realización de las vocales interiores en una o dos sílabas, los conceptos que se utilizan son los de hiato y sinéresis. Ha desaparecido el de diptongo o triptongo. Se ve en todos los ejemplos que da T. Navarro Tomás. Así en las palabras viaje, suave, cruel, aún, ahí, la pronunciación con el silabeo vi-á-je, su-á-ve, cru-él, $a$-ún, $a$-í es calificada de hiato, mientras que la pronunciación con el silabeo viá-je, suáve, cruél, áun, ái es ejemplo de sinéresis. ¿En qué se distingue el diptongo de la sinéresis en la pronunciación que silabea via-je? De hecho, lo que hace T. Navarro Tomás es reducir a dos las posibilidades: unión (sinéresis), separación (hiato).

${ }^{22}$ El efecto prosódico del hiato a que se refiere T. Navarro Tomás ha sido descrito tradicionalmente como sonido desagradable o cacofonía que resulta del encuentro de vocales. En la retórica latina (Cicerón, Quintiliano) se recomienda evitar en el discurso el encuentro de vocales entre palabras, que produce «hiulcas voces» 0 «hiulca verba», palabras en hiato. Fernando de Herrera hablaba de verso hiulco, que se evita con la sinalefa, que los griegos llaman sinéresis; es decir, se trata de verso con hiato, no de verso con sinéresis, como anotan los editores, Inoria Pepe y José María Reyes. Herrera, Fernando de: Anotaciones a la poesía de Garcilaso, edición de Inoria Pepe y José María Reyes. Madrid: Cátedra, 2001, p. 367. Mariano José Sicilia asocia el hiato a la abertura continuada de la boca «que se ocasiona por la pronunciación separada, consecutiva y uniforme de dos o más sonidos vocales». Y habla de sonidos hiulcos, cuando no hay sinalefa. SiciLia, M. J.: Lecciones elementales de ortología y prosodia, cit., t. II, 1827, pp. 210-212.

${ }^{23}$ Navarro Tomás, T.: Manual de pronunciación, cit., pp. 65-69. 
En Arte del verso, T. Navarro Tomás sigue hablando de hiato, «que resulta de separar silábicamente en la pronunciación las vocales inmediatas», tanto en la palabra como entre palabras, y de contracción de vocales en interior de palabra (sinéresis) o entre palabras (sinalefa). Pero no puede dejar de mencionar, muy de pasada, la diéresis «o disgregación del diptongo» para decir que «se usa en raras ocasiones». De hecho es la única mención que hace y parece motivada por la necesidad de definir un concepto muy presente en la tradición de la teoría métrica, más que porque piense en su rendimiento para la descripción. Las vacilaciones entre hiato y sinéresis, o entre hiato y sinalefa, «impiden encerrar el tratamiento de estos grupos en reglas simples y precisas». De sumo interés es el apartado dedicado a la vacilación en «los grupos con acento interiores de palabra» entre hiato y sinéresis, que se desarrolla «bajo influencias más imprecisas». Los poetas suelen aplicar una u otra forma en condiciones «aparentemente análogas»: «Finas y ocasionales diferencias de expresión determinan la preferencia de cada caso. Palabras como día, ahí y aún se tratan unas veces como bisílabas y otras veces como monosílabas. De manera semejante fluido, viuda, huida y ruido en unos casos presentan tres sílabas y en otros dos. Las oscilaciones de esta prosodia inestable ofrece entre los versos contrastes como los siguientes». Y sigue una lista de versos en que aparecen con silabeo distinto las palabras: suave, su-ave; cruel, cru-el; oceano, oce-ano; real, re-al; caen, ca-en; aún, a-ún; ruinas, ru-inas; viuda, vi-uda; sonriendo, sonri-endo ${ }^{24}$.

${ }^{24}$ Navarno Tomás, T.: Arte del verso. México: Colección Málaga [1959] 1968, 4. ${ }^{a}$ edición, pp. 14-18. Muy semejante al cuadro conceptual de T. Navarro Tomás en Arte del verso es el de Rafael Lapesa en su Introducción a los estudios literarios. El hiato, «pronunciación disílaba de vocales contiguas» se da tanto entre palabras como en el interior de una palabra; la sinéresis se da «cuando vocales contiguas interiores de palabra que de ordinario están en hiato, aparecen reducidas a una sola sílaba», como aérea, bisílabo en Espronceda gracias a dos sinéresis. La diéresis, que «consiste en escandir las vocales de un diptongo pronunciándolas con hiato (pi-e-dra, su-erte, por pie-dra, suer-te)», queda reducida a una mención, pues solo es legítimo preferir el hiato al diptongo «cuando las dos formas de dicción están admitidas», y entonces «no puede llamarse diéresis» al uso de la forma su- $a$-ve, $r u-i-n a, r u-i$-do. El verso «no debe deformar la pronunciación correcta», aunque tampoco hay que ignorar pronunciaciones antiguas o latinismos que explican escansiones como las siguientes: pi-e-dad, ju-i-cio, o-ra-ci-ón, ci-en-cia, victo-ri-o-so, o-ri-en-te. LAPESA Melgar, R.: Introducción a los estudios literarios. 
Las referencias de Tomás Navarro Tomás a una prosodia inestable, a finas diferencias de expresión o a la aparente libertad de elección de los poetas, nos dan pie para entrar en lo que se dice en los tratados y se hace en poesía con algunos ejemplos, en concreto con las palabras cruel, suave, fiel, ruido, ruina.

\section{cruel}

Empezamos con algunos de los datos que nos proporcionan los tratadistas. Sobre la palabra CRUEL, Nebrija no dice expresamente nada, aunque sí afirma que la combinación de vocales ue "puédese desatar mui pocas veces» ${ }^{25}$. Tampoco Caramuel menciona la palabra cruel, aunque respecto de la combinación ue, lo mismo que Nebrija, dice que se pronuncia como diptongo, y no da ningún ejemplo de separación ${ }^{26}$.

Con el autor de la primera ortología castellana, Mariano José Sicilia, la cosa cambia, cuando dice que cruel no lleva diptongo y se refiere a la escansión monosílaba de cruel como ejemplo de sinéresis, en el endecasílabo de Mro. González, Con cruel muerte pagó su alevosía. Antes había dicho que cruento, incruento, crueza no llevan diptongo ${ }^{27}$. Aunque Bello no trata de forma particular la palabra cruel, ésta entra en el grupo de combinación de débil átona y llena tónica, que unas veces forma diptongo y otras no, siendo más fácil la sinéresis, si no forman diptongo, que la diéresis, si lo forman (por ejemplo, en Dios) ${ }^{28}$. Eduardo Benot considera grupo adiptongal en cru-el, y da ejemplos de esta medida en el verso, al tiempo que considera mala contracción la medida monosílaba, que se encuentra en algún ejemplo de poesía, como en el endecasílabo de Martínez de la Rosa que cita,

Salamanca: Anaya, 1971, reimpresión, pp. 72-74.

${ }^{25}$ Nebrija, A.: Gramática, cit., p. 40.

${ }^{26}$ Dice: «confluunt et per modum diphtongi pronuntiantur». Caramuel, J.: Primus Calamus, II, cit., p. 32.

${ }^{27}$ SicILIA, M. J.: Lecciones elementales de ortología y prosodia, cit., t. IV, pp. 65, 6970; t. III, p. 214. Para José Gómez Hermosilla, la realización monosílaba de cruel es ejemplo de sinéresis, y la pronunciación ordinaria es bisílaba. Gómez HermoSILLA, J.: Arte de hablar en prosa y verso. Madrid: Imprenta Nacional, 1839, 2. ${ }^{\text {a }}$ ed., t. II, p. 120.

${ }^{28}$ Bello, A.: Principios de la ortolojía y métrica, cit., pp. 46-47. 
Allí lánguido yace el cruel guerrero ${ }^{29}$. Felipe Robles Dégano considera azeuxis, separación natural entre las vocales contiguas de cruel, y así se comprueba en el $94 \%$ de los casos que registra en poesía. No piensa que se deba a caída de la $d$ intervocálica de su origen latino (crudelis), como piensa la Academia. Claro que esto no impide el que en algún autor, como es el caso de Bernardo de Valbuena (1568-1627), se da sinéresis en el $80 \%$ de los ejemplos de $\mathrm{cruel}^{30}$. T. Navarro Tomás, en su Manual de pronunciación, registra la forma disílaba, cru-el (hiato), y la monosílaba, cruel (sinéresis), y habla de «tradición etimológica» para el frecuente hiato en esta palabra. En Arte del verso, ejemplifica con sendos versos la realización como hiato o como sinéresis de cruel, en el grupo de las vacilaciones de palabras con prosodia inestable ${ }^{31}$. De los datos anteriores se concluye que nadie habla de diéresis para la escansión bisílaba, sino que tal pronunciación o medida se considera separación natural (adiptongo, azeuxis o hiato), y en todo caso la pronunciación o medida monosílaba es un ejemplo de sinéresis.

\section{fiel}

Al mismo grupo de combinación de débil (absorbible, cerra$d a,+a l t a)$ y llena (absorbente, abierta, - alta) tónica pertenece también la palabra FIEL, que vamos a comentar seguidamente. Hablando del diptongo ie, dice Nebrija que puede desatarse en fiel, riel; y Juan Caramuel observa que fiel suele ser monosílabo, aunque Góngora disuelve la unión, como se ve en los ejemplos siguientes: Sino hospedado del fíél Lombardo; Fíeles a una

${ }^{29}$ B $\mathrm{EnOT}$, E.: Prosodia castellana, cit., t. II, pp. 12, 279, 286, 288.

${ }^{30}$ Robles DÉGano, F.: Ortología clásica, cit., pp. 284, 289, 355.

${ }^{31}$ Navarro Tomás, T.: Manual de pronunciación, cit., pp. 67, 158-159; Arte del verso, cit., p. 17. Curiosamente, como ejemplo de cruel monosílabo, reproduce T. Navarro Tomás el mismo verso de F. Martínez de la Rosa que ya había citado Benot. La Real Academia Española considera más frecuente el hiato en el grupo de $u+a, e$, $o$ acentuadas, si la consonante que precede a $u$ no es velar, como en cru-el. REAL ACADEMIa Española: Esbozo de una gramática de la lengua española. Madrid: Espasa-Calpe, 1973, p. 52. Real ACADEmia Española: Nueva gramática de la lengua española. Fonética y fonología. Barcelona: Espasa, 2011, p. 337, habla de las vacilaciones en la pronunciación de la combinación [+ alto] $(i, u)$ y [-alto] y se refiere a la palabra crueldad «como hiato o como diptongo en función de diversos factores de carácter espacial, estilístico o social. En ocasiones, la etimología o la analogía influyen en la solución fonética». 
pluma, que a passado ${ }^{32}$. Para Benot, lo normal es el diptongo en la pronunciación de fiel, aunque antiguamente se pronunciaba bisílabo «como compensación de la $d$ perdida de fidelis». Cinco ejemplos de versos de Calderón ilustran la medida bisílaba, pero, hoy, "perdida ya enteramente la conciencia etimológica, hacen mui mal los que escriben como bisílabo a fiel, diciendo $f i$-él» ${ }^{33}$. Felipe Robles Dégano sostiene que «naturalmente pide azeuxis», dada su procedencia de fidelis, y así lo hacen los poetas del XVI (con la excepción de Fray Luis), en Lope ya hay tantos diptongos como azeuxis, y después generalmente es diptongo como hoy, «aunque no debiera haberse cambiado el uso de los antiguos poetas que le pronunciaban con azeuxis, como Castellanos, Góngora, Rufo, Montesino y otros». La pasión del latinista se impone ${ }^{34}$. Tomás Navarro Tomás incluye la palabra fiel en el grupo de las que han normalizado la sinéresis aunque antes vacilaban, «y que aún, de vez en cuando, suelen aparecer con hiato en el lenguaje poético» ${ }^{35}$. A la vista de lo anterior, podría concluirse que fiel mantiene un resto de su origen en la posibilidad de ser bisílabo en el lenguaje versificado, posibilidad que ha ido disminuyendo en la historia de la poesía. No hay duda hoy de su pronunciación natural como monosílabo.

\section{suave}

Un último ejemplo de este grupo de combinaciones vocálicas es el de la palabra SUAVE. Caramuel califica como diéresis la forma trisílaba de suave, con cinco ejemplos de Góngora más otro con la palabra suavemente, pentasílaba ${ }^{36}$. Para Mariano José Sicilia, suave es trisílabo, mientras que para Bello, lo mismo que Diana, suave es arbitrariamente disílabo o trisílabo, es decir, «diptongo soluble, o dos sílabas que se prestan sin la menor

$\overline{32}^{32}$ Nebrija, A.: Gramática, cit., p.40; Caramuel, J.: Primus Calamus, cit., p. 29.

${ }^{33}$ Benot, E.: Prosodia, cit., II, pp. 12, 290. ¿Quiere esto decir que una persona con conciencia etimológica podría decir fi-el?

${ }^{34}$ Robles Dégano, F.: Ortología clásica, cit., p. 348.

${ }^{35}$ Navarro Tomás, T.: Manual de pronunciación, cit., p. 159.

${ }^{36}$ Caramuel, J.: Primus Calamus, cit., p. 24. Conviene corregir una errata en la traducción de esta obra de Caramuel, J.: Primer Cálamo, cit., p. 41, donde empieza el párrafo: «Alguna vez es disílaba en los Trísticos», debe decir «trisílaba», pues así lo pide el sentido y así lo dice el original: Interim in Tristichis ... fit trisyllabum (p. 24). 
violencia a la sinéresis» ${ }^{37}$. Nótese que Bello no prefiere una u otra pronunciación. No está muy clara la prosodia de suave para Benot, pues en un momento dice que por naturaleza es trisílaba, y que por sinéresis se hace bisílaba, pero dura; señala la doble posibilidad de medida en un mismo verso octosílabo de Calderón (sen-taos qu>el viento su-a-ve; sen-ta-os qu>el viento suave); el uso de los que hablan, por razones etimológicas o por otros motivos, deshace el diptongo de absorbible desacentuada y absorbente acentuada (dos ejemplos en versos de Lista, su- $a$ ve); la contracción en verso es mala (dos ejemplos de sua-ve en Arriaza $)^{38}$. Benot piensa como preferible la medida trisílaba de suave, y dura o mala la sinéresis. Felipe Robles Dégano ve siempre azeuxis en la combinación ua, como en sũave. De la lista de aparición con azeuxis o sinéresis en poesía clásica se comprueba la preferencia por la azeuxis, entre otros, en: Garcilaso (4 az. I 2 sin.), Herrera (56 az. / 0 sin.), Góngora (69 az. / 0 sin.), Lope (174 az. / 3 sin.), Quevedo (20 az. / 2 sin.) y un total de 1496 az. frente a 192 sin. en el corpus de poetas clásicos examinados. Es abrumador el dominio de suave trisílabo, y las sinéresis de Meléndez y Arriaza «son cosa algo extraña» ${ }^{39}$. T. Navarro Tomás califica de hiato la pronunciación como trisílabo, su-a-ve, y de sinéresis la de bisílabo, sua-ve. La tradición etimológica explica la frecuencia del hiato en su-a-ve. En Arte del verso, la palabra suave está en el grupo de las que vacilan entre el hiato y la sinéresis, con ejemplos de versos de Hermosilla (diéresis) y Arriaza (sinéresis) $^{40}$. Se impone la consideración trisílaba de suave, a pesar de las dudas de Bello.

${ }^{37}$ Sicilia, M. J.: Lecciones elementales de ortología, cit., t. III, p. 213; BELLO, A.: Principios de la ortolojía y métrica, cit., p. 48.

${ }^{38}$ Benot, E.: Prosodia castellana, cit., II, pp. 73, 77, 278, 287.

${ }^{39}$ Robles Dégano, F.: Ortología clásica, cit., pp. 267, 279, 293-294, 357.

${ }^{40}$ Navarro Tomás, T.: Manual de pronunciación, cit., pp. 68, 158-159; Arte del verso, cit., p. 17. El verso de Arriaza citado por T. Navarro Tomás, Suave respira el viento, el mar salado, está entre los del mismo autor citados por Benot. José Manuel Marroquín habla de diéresis permitida, y aun conveniente, en suave. Domínguez CAPARRós, J.: Contribución a la historia de las teorías métricas en los siglos XVIII y XIX. Madrid: CSIC, 1975, p. 199. Real ACADEMIa Española: Esbozo, cit., p. 48, señala como curiosidad que «frente a cuan-do, a-gua, etc., nuestra poesía clásica, acaso por influjo del italiano soave (pero ya /su-ave/ en Berceo, Himnos, BibAE, LVII, p. 144a), y aun a veces la moderna ha insistido en silabear su-a-ve». 


\section{ruido}

Como ejemplos de la combinación de dos débiles, cerradas o absorbibles, en el grupo ui, vamos a ver qué nos dicen los tratadistas de ruido y ruina. La palabra Ruido es trisílaba para Caramuel y la representa con tilde en las dos vocales, su forma de indicar la separación, rúído, con tres ejemplos de Góngora ${ }^{41}$. Para Mariano José Sicilia, la diéresis o separación de una sílaba en dos es ejemplificada con la palabra ru-i-do, trisílaba, pues más adelante considera que en ruido hay diptongo, aunque «se permite a los poetas con bastante frecuencia la diéresis» ${ }^{42}$. Bello habla de diptongo disoluble «o si se quiere dos sílabas que admiten fácilmente la sinéresis como en ruin, ruina, ruido, viuda» ${ }^{43}$. No da, pues, la preferencia al silabeo con diptongo o sin él. Para Benot, sin embargo, lo natural es el adiptongo, ru-i-do, y «por sinéresis (que suena mui mal al fin de verso)» se hace bisílaba, con ejemplo de Espronceda. Más adelante insistirá en que el buen versificador separa ru-ido, que se contrae malamente, como ilustra el ejemplo de tres versos con rui-do en Hermosilla ${ }^{44}$. Felipe Robles Dégano señala que primitivamente ruido tiene azeuxis, es decir, es trisílabo, y que por uso cambiado permite la sinéresis. La azeuxis viene explicada por la etimología (proceda de rugitus, como quiere la Academia, o de ruitum, supino de ruo, caer). La Academia dice que hay diptongo que los poetas disuelven, y de la lista del número de apariciones con azeuxis o diptongo en los poetas clásicos, F. Robles Dégano habla de «su natural azeuxis hasta que vino Quevedo al mundo». Por ejemplo, Herrera (3 az., 0 dipt.), Cervantes (8 az., 1 dipt.), Góngora (19 az., 1 dipt.), Lope (125 az., 7 dipt.), Quevedo (4 az., 21 dipt.) Calderón (6 az., 97 dipt. $)^{45}$. T. Navarro Tomás da la preferencia al diptongo sobre el hiato en la pronunciación de ruido, si bien señala que el hiato es más frecuente en verso que en la conversación y más en poetas antiguos que modernos. En Arte del verso, la palabra ruido está en el grupo de los ejemplos de vacilación entre hiato

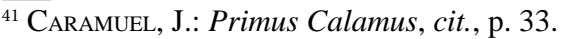

${ }^{42}$ SiciliA, M. J.: Lecciones elementales, cit., t. III, pp. 201-202, 218-219.

${ }^{43}$ Bello, A.: Principios de la ortolojía y métrica, cit., p. 49.

${ }^{44}$ Benot, E.: Prosodia castellana, cit., t. II, pp. 74, 286, 288.

${ }^{45}$ Robles Dégano, F.: Ortología clásica, cit., pp. 262-266.
} 
y sinéresis, con prosodia inestable. Espronceda, por ejemplo, la emplea en las dos formas ${ }^{46}$. En el caso de ruido, las opiniones son muy variadas: desde diptongo natural, que en poesía admite diéresis o hiato (M. J. Sicilia, Academia, Navarro Tomás), a las dudas sobre su pronunciación natural (Bello), su consideración como trisílaba que malamente admite sinéresis en verso (Benot) o trisílaba que cambia a bisílaba (Robles Dégano).

\section{ruina}

Muy cercana a la prosodia rítmica de ruido es la de la palabra Ruina. Dice Caramuel que tiene tres sílabas, con dos ejemplos de Góngora, rúína, rúínas. Aunque comenta también el verso endecasílabo de Góngora, O Argel; o de ruinas Españolas, donde tiene dos sílabas porque no se hace sinalefa $o A r^{47}$. Mariano José Sicilia incluye ruina en el grupo de ruido, con diptongo, si bien a los poetas se les permite la diéresis, como hemos visto. Bello incluye ruina también en el grupo de ruido, con sus mismas características prosódicas ${ }^{48}$. Eduardo Benot considera natural el adiptongo ru-i-na, que se hace bisílabo por sinéresis. En un mismo verso de Quevedo aparecen las dos formas: Tus ru-i-nas aumenten, i tus rui-nas. Como en el caso de ruido, el buen versificador hará trisílaba la palabra ruina, que se contrae malamente, con ejemplo también de esta mala contracción en Hermosilla ${ }^{49}$. La primitiva azeuxis de ruina va cambiando hacia la sinéresis, según Felipe Robles Dégano. La etimología (del latín, ruo) exige azeuxis, y esto es lo clásico, aunque la duda perceptible ya

${ }^{46}$ Navarro Tomás, T.: Manual de pronunciación, cit., p. 167; Arte del verso, cit., pp. 17-18. La Real ACAdEMia Española: Esbozo, cit., pp. 55-56, señala el diptongo uí en ruido y ruina, si bien en la poesía clásica es muy frecuente el hiato ru-ido, con ejemplo de Rubén Darío, ru-ina, con ejemplo Unamuno. En su Nueva gramática. Fonética, cit., p. 337, se refiere a las vacilaciones en el grupo ui, muy difíciles de regular, «dado el grado de libertad de los hablantes ante los factores que condicionan la aparición de uno u otro tipo de realización». A este grupo pertenecen dos de las palabras que estudiamos: ruido, ruina.

${ }^{47}$ Caramuel, J.: Primus Calamus, cit., p. 32, refiriéndose a ruinas: «quia primum O non eliditur per synaloepham, non habet nisi duas syllabas». Sin embargo el verso es medible perfectamente con sinalefa y con ru-i-nas trisílabo: Oar-gel-o-de-rui-nas-es-pa-ño-las.

${ }^{48}$ Sicilia, M. J.: Lecciones elementales, cit., t. III, pp. 218-219; Bello, A.: Principios de la ortolojía y métrica, cit., p. 49.

${ }^{49}$ Benot, E.: Prosodia castellana, cit., t. II, p. 74, 109, 286-288. 
en Quevedo y la moderna tendencia a la contracción permiten la sinéresis. Algunos de los datos de su lista de apariciones así lo dicen, como, por ejemplo: Herrera (4 az., 0 dipt.), Cervantes (7 az., 0 dipt.), Góngora (23 az. 1 dipt.), Lope (27 az., 3 dipt.) Quevedo (6 az., 11 dipt.), Calderón ( 2 az., 49 dipt.) ${ }^{50}$. Lo mismo que ruido, T. Navarro Tomás dice que se prefiere el diptongo en la pronunciación de ruina, aunque también se da el hiato, más en verso que en la conversación y más en poetas antiguos que modernos. En Arte del verso, entra lo mismo que ruido en el grupo de palabras que oscilan con prosodia inestable: ru-inas (Arolas), ruinas (Espronceda) ${ }^{51}$. En resumen, la prosodia de ruina tiene características semejantes a la de ruido.

\section{IV}

Después de este somero repaso a lo que las descripciones más conocidas de la pronunciación española nos dicen de las palabras que hemos elegido en nuestro estudio, vamos a completar con un pequeño muestreo de ejemplos. No hay que recordar que en la obra de Felipe Robles Dégano se encontrará el más amplio recuento referido al verso clásico español. Nosotros nos limitamos a un pequeño muestreo basado en la consulta de concordancias de algunas obras en la Biblioteca Virtual Miguel de Cervantes. Pasamos a dar cuenta de los resultados.

\section{Fray Luis de León}

En las Poesías (ed. Javier San José Lera, 2008), de Fray Luis de León, la palabra cruel aparece como bisílaba y sin crema en 18 ocasiones, y en otras dos ocasiones en que es bisílaba sí lleva crema o diéresis marcada (-iay, piedad crüel! Desconociese; los otros a crüel fierro metido); es monosílaba en dos ocasiones (tuviesen cruel antojo, heptasílabo; Y ansí del hado duro la cruel rueda). De la misma familia, la palabra CRUELDAD en tres ocasiones es trisílaba, pero solo lleva crema o diéresis en una de estas tres apariciones (su furia, crüeldad y tiranía), y en una ocasión es bisílaba (su dura suerte y tu crueldad culpando); y la palabra

\footnotetext{
${ }^{50}$ Robles Dégano, F.: Ortología clásica, cit., pp. 249, 262-266.

${ }^{51}$ Navarro Tomás, T.: Manual de pronunciación, cit., p. 167; Arte del verso, cit., pp. 17.
} 
CRUELMENTE es tetrasílaba en la única ocasión en que aparece en verso y lleva crema (para despedazarte crüelmente). Domina claramente la separación silábica del grupo ue en la palabra cruel y las de su familia, aunque no se descarta la forma diptongada. El criterio del editor a la hora de marcar tipográficamente la diéresis no es coherente.

El grupo vocálico ie es siempre en Fray Luis diptongo en FIEL, que aparece en 16 ocasiones, y en la única ocasión en que aparece cada una de las palabras INFIEL, INFIELES (en las infieles bárbaras entrañas; al modo infiel, tristeza, heptasílabo).

La palabra suave es trisílaba y lleva diéresis en dos ocasiones (de Favonio süave y amoroso; lanza mirra de sí y olor süave); en una ocasión es bisílaba (el suave olor, la no vista belleza). En SUAVEMENTE el grupo vocálico ua es diptongo (con la aplicada cera suavemente); o disílabo, aunque el editor no marca diéresis (maestros, tú en tañer suavemente). En Fray Luis, pues, aunque predomina la solución disílaba del grupo ua, es posible la forma diptongada. El editor, a la hora de marcar la crema o diéresis, no lo hace en una ocasión, referida a suavemente.

En el caso de la palabra Ruido, en una de las ocho ocasiones en que aparece en verso es bisílaba (con ruido sonoroso, heptasílabo), y en las otras siete es trisílaba y el editor marca siempre la diéresis, rüido ${ }^{52}$. No encontramos concordancias de la palabra ruina en la edición de Fray Luis que consultamos.

\section{Fernando de Herrera}

En los Sonetos (ed. Ramón García González, 2006), de Fernando de Herrera, el grupo ue en CRUEL, con 35 apariciones (de

$\overline{{ }^{52}}$ A propósito de ruido en Fray Luis de León es notable el despiste del texto del segundo verso de Canción a la vida solitaria tal como se edita en la antología comentada de Rico, Francisco: Mil años de poesía española. Barcelona: Planeta, 1996, p. 281, que dice: la del que huye del mundanal ruido. Teniendo en cuenta que ruido siempre es trisílabo en Fray Luis, para que el verso se mida como endecasílabo tal como figura en ese texto, habría que hacer sinalefa quehu, lo que no es posible por tratarse de $h$ - procedente de $f$ - latina (fugit $>$ huye). La sinalefa debe ir en yeel (huye el dicen otras ediciones, no huye del). Porque si no se hace la sinalefa que$h u$ en el texto de Rico, el verso exigiría una escansión totalmente desajustada al patrón del endecasílabo clásico: la-del-que-hu-ye-del-mun-da-nal-rui-do (acentos en $4 .^{\mathrm{a}}, 9 .^{\mathrm{a}}$ y $10{ }^{\mathrm{a}}$. Aquí ruido tendría que ser bisílabo; en las otras ediciones, es trisílabo, ru-i-do, que es la forma normal en Fray Luis). 
las que tres en plural, crueles, y dos en la palabra crueldad), es siempre bisílabo. El editor no marca nunca esta separación con crema o diéresis. Aparece la palabra fIEL en cuatro ocasiones, nunca lleva crema o diéresis, a pesar de que en dos ocasiones es bisílaba (tiembla el pecho fiel y me condena; Aquí do lloro en $t i$, fiel desierto). De los otros dos ejemplos, uno claramente es de fiel monosílabo (reino de amor no tiene fiel estado), pero el verso que dice por quien en pérdida busco fiel y lloro (verso 7 del soneto que empieza Ardía, en varios cercos recogido) resulta hipermetro, con doce sílabas, aun haciendo monosílaba la palabra fie ${ }^{53}$. El grupo ua en SUAVE (28 apariciones y 1 suavemente) siempre es bisílabo en F. de Herrera, si bien el editor nunca usa la diéresis para marcar la separación. Aunque las dos veces que aparece la palabra RUiNA es trisílaba, nunca se marca la separación con crema: En tus ruinas míseras contemplo; fatal ruina al bárbaro africano. No aparece la palabra RUIDo en la edición consultada de los Sonetos de F. de Herrera. Parece clara la tendencia de Herrera a separar los grupos vocálicos ue, ua, ui en los ejemplos estudiados y sólo hay prosodia variable en la palabra fiel.

\section{Luis de Góngora}

En tres obras de Luis de Góngora hemos realizado la consulta: Fábula de Polifemo y Galatea, Las firmezas de Isabela y Soledades. La edición digital, en 1999, de la Fábula de Polifemo y Galatea $^{54}$ nos muestra un ejemplo de CRUELDAD trisílaba, y el editor marca la separación con diéresis: armó de crüeldad, calzó de viento. La aparición de RUIDo en una ocasión y como trisílabo es señalada por el editor con diéresis -y acento innecesario sobre la i-: cien cañas, cuyo bárbaro rüído. De las seis veces que aparece la palabra SUAVE, cinco es trisílaba y el editor

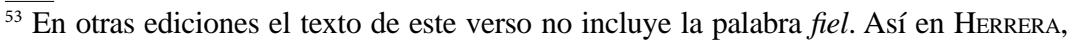
F. de: Poesía castellana original completa, ed. Cristóbal Cuevas. Madrid: Cátedra, 1997, 2. ${ }^{\text {a }}$ ed., p. 517: por quien, perdida, busco siempre i lloro. El verso con la palabra fiel tiene arreglo si se sustituye «en pérdida», que parece una errata, por "perdida», que tiene sentido más claro: por quien perdida busco fiel y lloro; además de ajustarse perfectamente a la acentuación del endecasílabo en 4, 6, 8 y 10.

${ }^{54}$ Edición digital a partir de Obras de Don Luis de Góngora [Manuscrito Chacón]. I, de la Biblioteca Nacional (España), Ms. Res. 45, ff.121-137. Edición facsímil. Málaga: RAE; Caja de Ahorros de Ronda, 1991, (Biblioteca de los clásicos, dirigida por José Lara Garrido, 1). 
marca siempre la separación del grupo ua con diéresis. En una ocasión, suaves es interpretado como bisílabo, sin diéresis: mas, con desvíos Galatea suaves; aunque quizá no sería desechable la medida: mas-con-des-ví-os-Ga-la-tea-su-a-ves. La consulta de las concordancias de FIEL, RUINA no da ningún resultado. Hay que destacar la coherente utilización de la crema o diéresis en la indicación de la separación de los grupos vocálicos en las palabras estudiadas en esta edición.

En la edición digital (1999) de Las firmezas de Isabela ${ }^{55}$, CRUEL es bisílabo en nueve de las diez apariciones, y monosílabo en una ocasión ( Ingrato! ¡Isabela! ¡Cruel!, octosílabo). El editor marca la separación de vocales con diéresis solo en dos ocasiones (octosílabos: ¡Ah crüel! Señora mía; esta confusión crüel). La palabra CRUELDAD es bisílaba en las dos ocasiones en que aparece (Huyendo de tu crueldad; donde la crueldad y el vicio). FIEL y palabras de su familia aparecen con diéresis marcada en ocho ocasiones, aunque en un verso fiel es monosílabo y no debe llevar diéresis: tal respuesta, amigo fiel, octosílabo. En otras dos ocasiones aparece sin diéresis, porque no hay separación del grupo vocálico ( Traidor! ¡Isabela! ¡Infiel!), aunque cabe la duda en la escansión del octosílabo: Que, aunque varia, es muy fiel, donde para que fiel sea monosílabo hay que hacer hiato en varia / es, pero podría pensarse en la sinalefa variaes y entonces fiel sería bisílabo: queaun-que-va-riaes-muy-fi-el (-). En cualquier caso, a pesar del ejemplo de uso no debido de crema o diéresis, parece clara la voluntad del editor por indicar gráficamente la separación de vocales cuando tiene lugar en el caso de fiel, cosa que no ocurría en el de cruel, como hemos visto. SUAVE es trisílaba en el octosílabo en que hace su única aparición en esta obra de Góngora: y de fecundo suave; sin embargo, no lleva marcada con diéresis la separación vocálica. Las dos veces en que aparece la palabra RUINA, esta admite el silabeo como trisílaba; con seguridad en el ejemplo del octosílabo: sus ruinas, sin cuidar; y con dudas en el octosílabo: mostrar aún en sus ruinas, donde ru-i-nas si se mide aún como monosílabo. Tampoco

${ }^{55}$ Edición digital a partir del Manuscrito Chacón: Obras, vol. III, Biblioteca Nacional (España), Res. 46, pp. 1-120. Edición facsímil. Málaga: Caja de Ahorros de Ronda, 1991, 3 vols. (Biblioteca de los Clásicos). 
en estos casos se marca la separación vocálica con diéresis.

En Soledades ${ }^{56}$ la búsqueda de concordancias de CRUEL no da ningún resultado. En palabras de la familia de FIEL el grupo vocálico está dividido en las dos ocasiones en que aparece, y así lo indica el editor con diéresis: que, espejos, aunque esféricos, fieles; infieles por raros. En las once ocasiones en que aparece una palabra de la familia de suAvE, el grupo vocálico ua no forma diptongo y así lo indica gráficamente el editor mediante la crema o diéresis siempre. Lo mismo ocurre en las seis ocasiones en que aparece la palabra RUIDo, siempre trisílaba; o en las seis apariciones de la palabra RUINA, siempre trisílaba. Esta edición es, pues, coherente en el uso de la marca gráfica de la separación vocálica en las palabras estudiadas, que en todos los casos presentan separación de los grupos vocálicos.

\section{José de Espronceda}

De José de Espronceda hemos consultado dos obras: El Estudiante de Salamanca y El Diablo Mundo. En la primera de ellas $^{57}$, la palabra CRUEL aparece dos veces y siempre como bisílaba; el editor marca gráficamente la diéresis en una ocasión (en el dodecasílabo, 6 + 6: compañero eterno su dolor crüel), pero no en la otra (en el endecasílabo: galvánica cruel, nerviosa y fría). FIEL es monosílabo en las cuatro ocasiones en que aparece. En las cinco apariciones de suAVE hay que contar tres sílabas. El editor marca la separación vocálica con crema o diéresis en cuatro ocasiones, pero no lo hace en el caso del eneasílabo anfibráquico o esproncedaico siguiente: suave amorosa canción (acentos en 2..$^{\mathrm{a}}$, 5. $^{\mathrm{a}}$ y 8. ${ }^{\mathrm{a}}$ ). En el caso de la palabra RUIDO, la encontramos tanto con tres sílabas métricas (en tres ocasiones), como más frecuentemente con dos sílabas (en seis ocasiones), y el editor marca la separación con diéresis en las tres ocasiones en que el grupo vocálico se separa. La consulta de la concordancia de la palabra RUINA no muestra ninguna aparición.

${ }^{56}$ Edición digital a partir de Obras de Don Luis de Góngora [Manuscrito Chacón] I, de la Biblioteca Nacional (España), Ms. Res. 45, ff. 193-260. Edición facsímil. Málaga: RAE; Caja de Ahorros de Ronda, 1991 (Biblioteca de los Clásicos, dirigida por José Lara Garrido; 1 ).

${ }^{57}$ Edición digital, en 1999, a partir de Poesías de don José de Espronceda: Madrid: Imprenta de Yenes, 1840. 
En las ocho ocasiones en que aparece, la palabra CRUEL es bisílaba en El Diablo Mundo ${ }^{58}$, pero el editor no indica nunca con crema o diéresis la separación silábica del grupo. La palabra de la misma familia, crueldad, siempre es bisílaba, con diptongo, las dos veces en que aparece. Siempre es monosílabo fIEL en sus tres apariciones. En ocho de las once ocasiones en que aparece, SUAVE es trisílaba, pero el editor solo lo marca dos veces. Una de las tres apariciones con diptongo es de la palabra suavemente. En diecinueve de las veinte ocasiones en que aparece, RUIDo cuenta dos sílabas, y solamente una vez es trisílaba (de una cercana casa y al ruido, endecasílabo), aunque el editor no lo marca con diéresis ${ }^{59}$. De la misma familia, ruidosa aparece una vez y es trisílaba, con diptongo (tan súbita y ruidosa carcajada, endecasílabo). La mitad de las seis veces en que aparece, RUINA es trisílaba, pero el editor no lo indica gráficamente nunca con crema o diéresis.

\section{Rubén Darío}

Hemos consultado tres obras de Rubén Darío: Prosas profanas, El canto errante y Canto a la Argentina. En la primera de ellas ${ }^{60}$, la palabra CRUEL es bisílaba en una ocasión, y no lo marca la diéresis (dodecasílabo 6 + 6: iy es cruel y eterna su risa de oro!); lleva diptongo en la forma de plural crueles (dodecasílabo: de historias que dejan en crueles instantes), y no es significativa para la cuestión cuando aparece en el poema en prosa El país del sol, pues no hay un patrón métrico para decidir. FIEL aparece una sola vez y como monosílabo (dodecasílabo 6 + 6: ;que tu fiel amada, que la luna ha muerto!). sUAve siempre es bisílabo en las diez ocasiones en que aparece. RuIDo, editado siempre sin diéresis, es bisílabo solo en una ocasión (dodecasílabo 7 + 5: retumbas en el ruido de las metrallas), y trisílabo, con separación del grupo vocálico, en tres ocasiones (hexadecasílabo $8+8: y$ el ruido con que pasa por la bóveda del cielo; decasílabo $5+5$ :

${ }^{58}$ Edición digital, en 1999, a partir de la edición de Obras poéticas de Don José de Espronceda, ordenada y anotada por J. E. Hartzenbusch. París: Baudry, Librería Europea, 1848.

${ }^{59}$ Sí lo hace Robert Marrast en su edición de la obra en Clásicos Castalia (81, p. 366) con crema sobre la $i$ : de una cercana casa, y al ruïdo (v. 5416).

${ }^{60}$ Edición digital, en 1999, a partir de la de París, Vda. de C. Bouret, 1901. 
como el ruido de un caracol; Se oye el ruido de claras linfas). Una vez solo aparece la palabra RuINA y es bisílaba (dodecasílabo 6 + 6: y el rojo cometa que anuncia la ruina).

En El canto errante ${ }^{61}$ el grupo vocálico ue forma diptongo en las dos ocasiones en que aparece la palabra CRUEL (alejandrino 7 + 7: que temen los que temen el cruel vómito negro; octosílabo: menos crueles mordeduras). FIEL aparece una vez y es monosílabo (alejandrino 7 + 7: ¿Me permites, Chocano, que, como amigo fiel). sUAVE es bisílaba en una ocasión (alejandrino $7+7$ : dentro mi cráneo pasa una suave tormenta) y trisílaba en las otras dos ocasiones, sin que el editor lo señale gráficamente con diéresis (alejandrino 7 + 7: al suave aliento de las islas Baleares ${ }^{62}$; octosílabo: -¿Por qué si era yo suave). Solo en una de las siete ocasiones en que aparece el grupo ui es diptongo en la palabra RUIDO (endecasílabo: Y escuché el ronco ruido de trompeta), pero el editor no marca gráficamente la separación en las seis ocasiones en que cuenta tres sílabas. La búsqueda de las concordancias de RUINA no muestra ningún resultado.

En Canto a la Argentina. Oda a Mitre y otros poemas ${ }^{63}$, el grupo vocálico ue en la palabra CRUEL aparece como diptongo (en tres ocasiones: eneasílabo, menos cruel con la especie humana; octosílabo: ¿A qué los crueles filósofos ?64 ; alejandrino $7+$ 7: ayer has ofrecido en holocausto cruel) o con separación entre las vocales, que el editor no marca gráficamente (alejandrino $7+$ 7: los celos, las crueles insidias los espantos ${ }^{65}$ ). FIEL es monosílabo las tres veces que aparece, aunque cabe la duda en un caso en que el contexto de eneasílabos propiciaría la separación del

${ }^{61}$ Edición digital, en 2005, a partir de la edición de Madrid, Mundo Latino, [s.a.] (Madrid: Tipografía Yagües, 1918), (Obras completas; 16).

${ }^{62}$ Este verso es prosódicamente ambiguo. Para que suave sea trisílabo hay que medir así: al-su-a-ve-a-lien-to // de-las-is-las-Ba-lea-res, con hiato ve-a en el primer hemistiquio y sinéresis en lea, del segundo hemistiquio. Pero tratándose de un alejandrino de Rubén Darío cabe otra medida: al-sua-vea-lien-to-dé (-) // las-islas-Ba-le-a-res.

${ }^{63}$ Edición digital, en 2005, a partir de la edición de Madrid, Mundo Latino, [s.a.] (Madrid: Tipografía Yagües, 1918), (Obras completas; 9).

${ }^{64}$ Dada la fluctuación silábica que se aprecia en el poema, se ha elegido esta escansión por el contexto eneasílabo en el primer caso, y porque sigue un octosílabo con estructura similar en el segundo ejemplo: ¿A qué los falsos crisóstomos?

${ }^{65}$ En este verso, el texto de las ediciones modernas mide crueles como bisílabo: los recelos, las crueles insidias, los espantos. 
grupo (eneasílabo posible: que tiene por fiel el istmo). SUAVE se mide como bisílabo en las tres ocasiones en que aparece. RUIDO cuenta dos sílabas métricas en las tres apariciones, y ruina en las dos ocasiones en que aparece también es bisílaba.

\section{Juan Ramón Jiménez}

En la Antología de textos juanramonianos, de la Biblioteca Virtual Miguel de Cervantes ${ }^{66}$, no aparece ningún caso de la palabra CRUEL, y las seis veces que aparece en verso la palabra FIEL es monosílaba, lo mismo que la única aparición de infiel es bisílaba. Encontramos suAve con prosodia inestable, como bisílaba en tres de las seis ocasiones en que aparece en verso regular (octosílabo: nombre suave, que era el nombre; alejandrino $7+7$ : Sé que mi pena tiene aquella letra suave; del crepúsculo suave le florecía el sueño); como trisílaba en dos ocasiones (eneasílabo: por los suaves labios rojos; octosílabo: en vuelo de luz suave); y cabe la medida bisílaba o trisílaba en el eneasílabo: tierna, suave agua redonda (si se hace hiato ve/a, es bisílaba; pero cabe la siguiente división en sílabas métricas: tier-na-su-a-vea-guare-don-da). En el caso de suave trisílaba, los editores no marcan la separación del grupo vocálico con crema o diéresis. La única vez que aparece en verso RUIDo es palabra trisílaba: alejandrino $7+7$, te arreglabas la toca, el velo y sin ruido, aunque cabe la medida bisílaba si se hace un hiato en lo/y. RuinA aparece en

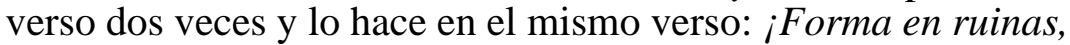
ruina de la esperanza! El verso es el número 15 del poema de Historias, que lleva el número 40 en la antología y que empieza Igual que una magnolia. Los 26 versos del poema son heptasílabos, endecasílabos y un eneasílabo, pero el único endecasílabo problemático es el del ejemplo, ya que es endecasílabo si medimos ruinas, ruina como bisílabas, pero entonces resulta un endecasílabo de acentuación no canónica en $1 .^{\mathrm{a}}, 3 .^{\mathrm{a}}, 5^{\mathrm{a}}$ y $10 .^{\mathrm{a}}$. Midiendo ruina como trisílaba resultaría un verso tridecasílabo, bastante raro en el contexto métrico del poema.

"66 JimÉNEZ, Juan Ramón: Antología de textos juanramonianos, compiladores Javier Blasco, Teresa Gómez Trueba. Alicante: Biblioteca Virtual Miguel de Cervantes, 2008. 


\section{Garcilaso de la Vega}

Además de los textos consultados en la Biblioteca Virtual Miguel de Cervantes, se ha hecho una lectura de las Obras de Garcilaso, editadas por Tomás Navarro Tomás ${ }^{67}$. Encontramos una aparición única de la palabra cruel y es bisílaba (Elegía I, v. 191: con proceso cruel y riguroso), y en las cinco ocasiones en que hemos encontrado la palabra de su familia, crueza, hay separación del grupo vocálico también, como, por ejemplo: no bastando su fuerza a mi crueza (Soneto XXXIII, v. 7). No hemos encontrado la palabra fiel, ni su compuesto infiel. La palabra SUAVE es más veces trisílaba (en cuatro ocasiones) que bisílaba (dos ejemplos). Trisílaba, por ejemplo, en: las verdes selvas con el son suave (Égloga III, v. 295); bisílaba, por ejemplo, en: el suave olor del prado florecido (Égloga II, v. 15). En ninguna ocasión señala con crema o diéresis la separación del grupo ue, ua. Salvo en el ejemplo del verso 98 de la Canción IV (la claridad contempla, el ruido siente), en todas las otras ocasiones en que la encontramos (hemos contado diez veces) la palabra RUIDO es trisílaba, y en seis de estos casos Tomás Navarro Tomás acentúa la í; nunca señala con crema o diéresis la separación del grupo ui. Por ejemplo, verso 13 de ÉGLOGA II: El dulce murmurar de este ruído; frente al verso 164 de ÉGLOGA I, por ejemplo: y con las simples aves sin ruido. RUINA cuenta tres sílabas en la única ocasión en que la hemos encontrado, Elegía I, v. 200, y Navarro edita acentuando gráficamente la í: del grave peso y de la gran ruína.

Aunque no son escasos los ejemplos de separación del grupo vocálico formado por $i$ átona más $e, o$ y sobre todo $a$ tónicas, no usa Tomás Navarro Tomás casi nunca la señal gráfica de la crema o diéresis para marcar la separación del grupo silábico. Hemos encontrado tres ejemplos: y el antiguo valor italiano (Soneto $X X X V$, v. 6), aunque esta misma palabra, italiano, con separación del grupo vocálico, es editada sin crema también en el verso 1545 de la Égloga II: El cauto italiano nota y mira, si bien en este caso cabe la interpretación de italiano como palabra

${ }^{67}$ Garcilaso: Obras, edición, introducción y notas de Tomás Navarro Tomás. Madrid: Espasa-Calpe (1924), 1970, novena edición (Cásicos Castellanos, 3). 
tetrasílaba haciendo un hiato en to/i. Otro ejemplo de uso de diéresis se refiere a la palabra odiosas, en el Soneto XVI, v. 1: No las francesas armas odïosas. La posibilidad de hiato cho/ el explicaría que no use la diéresis en el verso 160 de la Égloga III, interpretando entonces odioso como trisílabo: quien siente al pecho el odioso plomo. Un tercer ejemplo de uso de diéresis nos lo ofrece el verso 172 de la Elegía I: con luenga esperïencia sabidores. Encontramos, sin embargo, ejemplo de la misma palabra con doble prosodia y no se indica gráficamente la separación en el caso de piadoso, casi siempre palabra trisílaba, pero parece tetrasílaba en el verso 295 de la Elegía I, a no ser que se hiciera un hiato en si/el: Si el cielo piadoso y largo diere, donde la separación de las sílabas métricas sería: siel-cie-lo-pi-a-dosoy-lar-go-die-re.

Separaciones del grupo silábico interior de palabra sin indicación gráfica por medio de crema o diéresis tenemos en los casos de: riendo, huida, juicio, perjuicio, Piérides, viola, fiar, glorioso / a, Diana, quieto, variada, desvariadas, resfriado, virtuoso, frutuoso, confianza, desconfianza, desconfiado, gloriosa, criaban, crianza, guiara, viaje, variadas, variando, variable, demasiado, enfriaba. Como vemos, no se entiende muy bien cómo se marca diéresis en palabras como italiano, odiosas y experiencia y no se hace en los casos de las palabras de la lista anterior. Riendo es trisílaba siempre que aparece, y la separación del grupo ie es muy llamativa: con ese que de mí se está riendo (Egloga I, v. 180); ¿Y tú, ingrata, riendo (Égloga I, v. 392); vio que estaba riendo de su espanto (Égloga II, v. 1320). Quizá en el segundo ejemplo sea admisible la medida con hiato tú/in ${ }^{68}$.

${ }^{68}$ María Dolores Martos, editora, junto a José Lara Garrido, de Tejada PáEz, Agustín de: Obras poéticas. Sevilla: Fundación José Manuel Lara, 2011 (Cásicos Andaluces), me proporciona los ejemplos de uso de crema en los casos de separación en los grupos vocálicos de prosodia más inestable (dos cerradas con acento en una de ellas, o cerrada átona y abierta tónica) en las siguientes palabras: inquïeta, inquïeto, quïeto, desvïados, varïadas, Dïana, glorïoso, indïanas, guïada, guïando, guïaron, guïado, rocïando, Orïón, deïdades, Ixïón, vïolentos, Trïones, sicilïano, crïada, crïado, destruïda, vïaje, dïáfanos, Santïago, Orïente, radïante, Sïon, confianza, Trïones, fieles, Equïón, confianza, fiadas, cambïantes, Ixïón, rïeles, desafiando, vïolas, tïara, porfiar, süave, süaves, crüel, crüeles, rüido, ruïdo, rüina, ruïna, jüicios, tempestüoso, montüosa, suntüosos, viüda, fructüosos, sumptüosas. La lista, modelo de atención a la prosodia rítmica de las combinaciones 
La primera impresión, después de lo que se ha dicho sobre la prosodia de los grupos de vocales en interior de palabra $-\mathrm{y}$ lo que se ha hecho con los mismos en la edición de los textos en verso-, es la de una diversidad de maneras a la hora de explicar y valorar los distintos usos. Variedad que tiene sus raíces en la inestabilidad del uso en muchos casos. El verso, sin embargo, tiene la ventaja de ofrecer un patrón para fijar la prosodia de cada palabra y a partir de ahí se dispone de un ejemplo objetivo sobre el que discutir, para valorarlo positiva o negativamente, como normal, como abuso (licencia) o como variación admisible. Que en estos juicios no hay coincidencia, lo hemos visto, y aquí está presente la historia de la lengua artística.

¿Por qué no simplificar y hablar, como ya hacía Caramuel, de monosílabo y disílabo para las vocales interiores contiguas, ya sea por naturaleza o por figura ${ }^{69}$ ? Con la mentalidad objetiva del estudio científico, la descripción de la sílaba métrica considera solo dos posibilidades en el grupo de vocales: unión (llámese monosílabo, diptongo, sinéresis o zeuxis) o separación (llámese disílabo, adiptongo, hiato o azeuxis $)^{70}$. Y cuando se trate de una descripción objetiva es muy legítimo simplificar adoptando términos que estén desprovistos de valoraciones que tienen que ver con el concepto de figura. En este sentido, diéresis parece el término más difícil de justificar, dado lo problemático que resulta objetivar el concepto de diptongo -base de la definición

vocálicas más problemáticas en la edición de textos en verso, recoge términos coincidentes con los de Garcilaso con separación del grupo vocálico que hemos mencionado.

${ }^{69}$ La naturaleza para Caramuel significa de acuerdo con el origen («nativitatem et originem»), y las figuras son: sinéresis (hacer monosílabo un disílabo natural: desafí-o exige desafi-aron, y si se hace desa-fia-ron es por sinéresis), diéresis (hacer disílabo un monosílabo natural: inge-nio exige inge-nio-so, y si se hace ingeni-oso es por diéresis). Caramuel, J.: Primus Calamus, cit., p. 25.

${ }^{70}$ Torre, E.: «Zeuxis y azeuxis en la configuración silábica». Rhythmica, 2011, IX, 9, pp. 183-199, lleva la lógica de la descripción objetiva a extender las denominaciones de zeuxis (término que él propone por primera vez para designar la unión) y azeuxis (término empleado por Robles Dégano para la separación natural de grupos interiores) para la descripción de todo tipo de unión o separación en grupos de vocales interiores o entre varias palabras. Sobrarían, pues, en la descripción métrica los conceptos de diptongo, sinéresis, sinalefa, sustituidos por el neologismo zeuxis; hiato, diéresis, dialefa, sustituidos por azeuxis. 
de diéresis- para la unión natural de vocales en el uso. Algo semejante ocurre con sinéresis, aunque ha tenido más suerte para designar la unión de vocales eludiendo los casos de diptongos problemáticos.

Hay, sin embargo, razones que aconsejan la atención a los hechos a que se refiere la terminología tradicional, aparte de la justificación que todo conocimiento histórico tiene en los estudios humanísticos, si queremos comprender la tradición de nuestras disciplinas. No olvidemos que las ciencias del espíritu o humanidades son en esencia histórico-interpretativas. Así, según la forma como un analista califique la contigüidad de vocales interiores en la sílaba métrica (hiato o azeuxis, diptongo, sinéresis, diéresis), estos términos nos dicen algo más sobre cómo se concibe el fenómeno descrito. Pues, si habla de diéresis es porque piensa como natural el diptongo en el caso analizado; si de sinéresis, porque lo natural es la azeuxis. Lo natural en interior sería azeuxis -y sobre ella la figura de la sinéresis- y diptongo -sobre él la figura de la diéresis. Y esto importa como base para comentar la expresividad del verso. La cuestión es importante y está viva porque hay conciencia del problema de cómo proceder, sobre todo en los casos de prosodia variable. Problema que han visto nuestros tratadistas desde el principio (M. J. Sicilia o Bello, por ejemplo), porque el uso natural tampoco es tan fijo como desearíamos, ni hay una norma segura en todos los casos; un mismo poeta juega con las posibilidades de la prosodia variable ${ }^{71}$.

Insisto en una última cuestión, que traté en el trabajo sobre la diéresis mencionado al principio, y que se refiere a la edición de textos en verso. La norma académica en su Ortografía de 1999 establece la posibilidad del uso de la crema o diéresis en «la primera vocal de un posible diptongo, para indicar que no existe» (rüido). En su edición de 2010 se amplía notablemente la descripción del uso de la crema o diéresis, y como notas destacables cabe señalar: no se indica que deba colocarse sobre la primera

${ }^{71}$ Sor Juana Inés de la Cruz, en un mismo endecasílabo, mide como monosílabo fiel y como trisílabo infiel -o como bisílabos ambos-: en el fiel infiel con que gobierna (Primero sueño, v. 164). El grupo ie, pues, tiene un comportamiento distinto en cada una de las dos palabras. 
vocal, sino que «suele colocarse sobre la vocal cerrada», y si se trata de dos vocales cerradas, entonces «generalmente» va sobre la primera (rüido, vïudez); se evita hablar de diptongo, y sí se hace de «elementos de una secuencia vocálica», aunque «lo más habitual» es encontrar la diéresis sobre una de las vocales de un diptongo, que se deshace. Proporciona, además, información adicional muy interesante sobre la historia del variado uso de este signo $^{72}$. Es evidente que ha habido una preocupación desde Fernando de Herrera a Felipe Robles Dégano, pasando por Juan Caramuel o Eduardo Benot, por indicar gráficamente alguno de los fenómenos relacionados con la contigüidad de vocales, en el verso principalmente. La Ortografía académica no pasa de referencias generales, como no puede ser de otra manera, dada la anarquía reinante en la edición de textos, hoy y en el pasado. ¿Es posible un acuerdo? Quizá partiendo del concepto académico de diptongo ortográfico (abierta precedida o seguida de cerrada átona; dos vocales cerradas distintas), se podría proponer el uso de crema o diéresis para la indicación de la separación de dichas vocales en sílabas métricas distintas, como comentamos en nuestro trabajo sobre la diéresis ${ }^{73}$. Lo que no se generalizado es un sistema para indicar la sinéresis como el ideado por Fernando de Herrera (tilde en forma de dos acentos seguidos sobre la primera vocal del grupo).

Ante los problemas que para la sílaba métrica presenta la determinación de la misma cuando hay vocales en contacto en interior de palabra, quizá la única solución sea conocer la realidad de las divergencias entre quienes se han ocupado de la cuestión y tratar de comprender las razones de tales diferencias, que en ocasiones dan la impresión de ser laberínticas, como decía Marcelino Menéndez Pelayo en el prólogo al libro de Felipe Robles Dégano. Porque parece que todo intento de simplificación forzosamente prescinde de matices que tienen que ver con la percepción como fenómeno normal o como fenómeno expresivo de hechos que se suelen calificar como licencias poéticas. Si añadimos que lo normal es lo que está en la historia, cambiante por

\footnotetext{
${ }^{72}$ Real Academia Española: Ortografía de la lengua española. Madrid: Espasa, 1999, p. 82; 2010, pp. 280-281.

${ }^{73}$ Domínguez Caparrós, José: Nuevos estudios de métrica, cit., pp. 119-123.
} 
naturaleza, se comprenderá la imposibilidad de explicar con una regla simple lo que ocurre en la métrica de la poesía española de estos últimos quinientos años. No hay más remedio que tener presente el uso poético y la explicación de dicho uso por parte de los tratadistas de métrica. Es lo que hemos tratado de ilustrar con el repaso a algunas teorías y la descripción del uso de unas palabras características. 